\title{
Heterogeneity within youth with childhood-onset conduct disorder in the ABCD study
}

\author{
Sarah J. Brislin, Meghan E. Martz, Lora M. Cope, Jillian E. Hardee, Alexander Weigard, Mary M.
}

Heitzeg

University of Michigan, Department of Psychiatry

Role of Funding Source: This work was supported by funding from the National Institute on Alcohol Abuse and Alcoholism (T32 AA007477, and K01 AA024804, K01027558) and the National Institute on Drug Abuse (K01 DA044270). Data used in the preparation of this article were obtained from the Adolescent Brain Cognitive Development (ABCD) Study (https://abcdstudy.org), held in the NIMH Data Archive (NDA). This is a multisite, longitudinal study designed to recruit more than 10,000 children age 9-10 and follow them over 10 years into early adulthood. The ABCD Study is supported by the National Institutes of Health and additional federal partners under award numbers U01DA041048, U01DA050989, U01DA051016, U01DA041022, U01DA051018, U01DA051037, U01DA050987, U01DA041174, U01DA041106, U01DA041117, U01DA041028, U01DA041134, U01DA050988, U01DA051039, U01DA041156, U01DA041025, U01DA041120, U01DA051038, U01DA041148, U01DA041093, U01DA041089, U24DA041123, U24DA041147. A full list of supporters is available at https://abcdstudy.org/federal-partners.html. A listing of participating sites and a complete listing of the study investigators can be found at https://abcdstudy.org/consortium_members/. ABCD consortium investigators designed and implemented the study and/or provided data but did not necessarily participate in analysis or writing of this report. This manuscript reflects the views of the authors and may not reflect the opinions or views of the NIH or ABCD consortium investigators.

The ABCD data repository grows and changes over time. The ABCD data used in this report came from DOI: 10.15154/1504041. DOIs can be found at http://dx.doi.org/10.15154/1504041.

Acknowledgements: Authors have no conflicts of interest to report. A pre-print of manuscript has been made available online (https://psyarxiv.com/shp6c/).

Total Words: 8,997

Tables: 4 (1 supplemental table)

Figures: 2 


\section{Abstract}

The purpose of this study was to examine if personality traits can be used to characterize mechanistic subgroups of youth diagnosed with childhood-onset conduct disorder (CD). Participants were 11,552 youth from the Adolescent Brain Cognitive Development study. Data used in this report came from DOI: $10.15154 / 1504041$ ( $M$ age 9.92; 45.3\% female, $49.6 \%$ white, $19.0 \%$ Hispanic), a subset of whom $(n=365)$ met criteria for CD. Latent profile analyses (LPA) were used to define groups of individuals with CD based on self-report measures of impulsivity, punishment sensitivity, reward response, and callous-unemotional traits. Follow up analyses determined if these groups differed on clinically relevant variables including psychopathology, environmental risk factors, social risk factors, and neurocognitive functioning. Participants with a CD diagnosis scored significantly higher on psychological, environmental, social, and neurocognitive risk factors. The LPA revealed three unique profiles, which differed significantly on liability for broad psychopathology and domain-specific liability for externalizing psychopathology but were largely matched on environmental and social risk factors. These unique configurations provide a useful way to further parse clinically relevant subgroups within youth who meet criteria for childhood-onset $\mathrm{CD}$, setting the stage for prospective longitudinal research using these latent profiles to better understand the development of youth with childhood-onset CD.

General Scientific Summary: While previous research has shown that youth that display aggressive and antisocial behavior at a young age are at greater risk for continuing this behavior into adolescence and adulthood as well as having other comorbid mental health problems, age of onset still defines a relatively heterogenous group. In this study we used additional markers of importance to define three unique groups beyond age of onset of antisocial behavior. The results suggest that these groupings can provide additional, clinically relevant information that may serve to predict future trajectories of behavior. 


\section{Introduction}

Conduct disorder (CD) is a set of serious emotional and behavioral problems that manifests in children and adolescents, characterized by repetitive and persistent patterns of antisocial and rulebreaking behavior. Individuals with childhood-onset CD represent a particularly high-risk group as they are more likely to have a persistent life course of $\mathrm{CD}$ and chronic antisocial behaviors compared to adolescent-onset subtypes (Moffitt, 1993). Childhood-onset CD is also associated with a number of unique risk factors, including comorbid psychopathology and environmental influences (for review, see (Fairchild et al., 2019). However, there is evidence that a significant number of youth with childhoodonset CD desist from antisocial behavior by early adulthood (Odgers et al., 2008), suggesting that age of onset alone still designates a relatively heterogeneous group. Additional factors such as callousunemotional $(\mathrm{CU})$ traits, impulsivity, and reactivity to punishment and reward have also been shown to designate subgroups of children with CD (Frick et al., 2014; Longman et al., 2016; Moffitt et al., 2008; Platje et al., 2018), indicating that these traits may further clarify the heterogeneity within this high-risk group. Therefore, the current study utilized person-centered analyses in a large, diverse sample of emerging adolescents to determine if individual differences in relevant traits can define clinically meaningful subgroups of youth with childhood-onset CD.

Research on CD has focused on age of onset as a way to predict severity and recidivism. Seminal work has supported the distinction between a childhood-onset CD group, who begin showing conduct problems as early as preschool or early elementary school (Lahey \& Loeber, 1994), and an adolescentonset CD group, who begin displaying antisocial behavior with the onset of puberty (Moffitt, 1993). Research on the outcomes of these two subtypes of CD indicates that individuals with childhood-onset are more likely to continue showing antisocial behaviors into adolescence and adulthood relative to those whose behavior onsets in adolescence and are more likely to desist in adulthood (Moffitt et al., 2002). Childhood-onset CD is thought to reflect a more severe condition, potentially influenced by genetic predispositions, neuropsychological deficits, and exacerbated by childhood familial risk factors 
(e.g., parental psychopathology, family conflict) (Moffitt, 1993; Moffitt et al., 2002). While the age of symptom onset is clinically relevant, the designation does not necessarily define a homogeneous group. Therefore, additional information regarding where these youth fall on relevant personality traits may inform our understanding of heterogeneity within this diagnosis.

The CD diagnosis is associated with variation in a number of personality dimensions that may further define heterogeneity within youth diagnosed with childhood-onset CD. There are wellestablished links between childhood-onset CD symptoms and greater trait impulsivity, manifesting in comorbid diagnosis of ADHD (Beauchaine et al., 2010; Colledge \& Blair, 2001; Haas et al., 2017; Snyder et al., 2004; White et al., 1994). Youth diagnosed with childhood-onset CD have higher rates of comorbid ADHD compared to those with adolescent-onset CD (Connor et al., 2007; Silberg et al., 2015) and the presence of a comorbid ADHD diagnosis predicts the persistence of antisocial behavior into adulthood (Silberg et al., 2015). These findings suggest that the presence of higher levels of trait impulsivity reflect a greater risk for persistent antisocial behavior and may serve to further differentiate a high-risk group of youth.

CU traits are another personality feature that is known to increase risk for persistent antisocial behavior in youth. High levels of CU traits are exhibited by a subset of youth who meet criteria for CD (designated by the Limited Prosocial Emotions specifier in DSM-5) (Blair et al., 2014). Researchers have found that youth high in CU traits have a more severe and stable trajectory of problem behavior (Frick \& Dickens, 2006; Frick \& White, 2008; Rowe et al., 2010) but also may have less anxiety, fearfulness, and sensitivity to punishment (Frick, 2012). Consistent with broader research on psychopathy in adults (Patrick \& Drislane, 2015; Venables et al., 2014), previous work suggests that, although impulsivity and CU traits are often correlated, these personality dimensions are dissociable and can be thought of as distinct pathways that lead to CD symptoms in youth (Fanti et al., 2018; D. Pardini et al., 2006; Sica et al., 2019; Urben et al., 2018). Research suggests that heightened levels of CU traits designate a significantly more severe group of youth, even among those who meet criteria for childhood- 
onset CD suggesting that level of CU traits is a clinically relevant dimension to quantify even among youth with childhood-onset CD (McMahon et al., 2010; Pardini \& Fite, 2010). Therefore, impulsive and CU traits represent two dimensions that, through different configurations, could produce different clinical outcomes for youth with a CD diagnosis.

Altered sensitivity to reward and punishment, constructs that also are particularly relevant to broader research on antisocial behavior (Arnett, 1997; Ross et al., 2007), have likewise been linked to CD. Specifically, research has found that youth who display CD symptoms have heightened sensitivity to reward and reduced sensitivity to punishment (Byrd et al., 2018; Fairchild et al., 2008; Fonseca \& Yule, 1995; Morgan et al., 2014; Syngelaki et al., 2013), with some evidence to suggest this is more pronounced in youth with childhood-onset CD (Fairchild et al., 2009), although inferences about the former have been somewhat inconsistent between samples and measurement modalities (Byrd et al., 2014). Despite these findings, researchers have also found evidence for a subgroup of youth with CD and co-morbid anxiety disorders (i.e., psychopathology marked by hyperreactivity to threat and punishment) who demonstrate more antisocial behaviors relative to those without co-occurring internalizing psychopathology (Polier et al., 2012). Therefore, trait sensitivities to reward and punishment represent another two dimensions whereon an individual might differ but still meet criteria for CD. As these traits are closely linked to distinct neural and biological systems (Arnett, 1997; Kim et al., 2015; Simon et al., 2010), determining how they co-occur could be informative for understanding the etiologic pathways to early expression of $\mathrm{CD}$.

Taken together, this work demonstrates that an array of mechanistic dimensions contribute to the early emergence of $\mathrm{CD}$ in youth. Whether these dimensions contribute to heterogeneity and personspecific processes in $\mathrm{CD}$, including the formation of mechanistic subgroups through dimensional interactions, has yet to be explored. One likely reason for this limitation is that methods for characterizing heterogeneous subgroups, such as latent profile analysis (LPA), often require considerably larger sample sizes than those typically present in the CD literature (Peugh \& Fan, 2013). 
While CD has a relatively low rate of diagnosis (lifetime prevalence of 9.5\%; Nock et al., 2006), data from the Adolescent Brain Cognitive Development (ABCD) study are uniquely well-suited to examine subgroups within this diagnosis due to the large overall sample size and comprehensive assessments of participants and their parents.

The current study sought to first determine the trait profile of youth diagnosed with childhoodonset $\mathrm{CD}(\mathrm{CD}+)$. Given that this disorder is defined by impulsive, unconstrained behavior, we hypothesized that individuals meeting criteria for childhood-onset CD would have significantly higher rates of impulsivity, lower responsivity to punishment, higher responsivity to reward, and higher levels of callous traits than the non-CD group (CD-). Given previous research detailing childhood-onset CD (Moffitt et al., 2008; Snyder et al., 2004) we also hypothesized that the CD+ group would have a higher proportion of males, lower levels of socioeconomic advantages (e.g., household income, parental education) and environmental enrichment (e.g., school environment, family conflict), higher rates of general psychopathology, and lower neurocognitive functioning.

Next, we predicted that different trait profiles could be defined using information regarding trait levels of impulsivity, responsivity to reward and punishment, and CU traits. To our knowledge, this is the first study to examine heterogeneity on these traits simultaneously within youth with childhoodonset $\mathrm{CD}$; therefore, there is no previous research defining how these trait profiles might emerge. Based on research describing CU traits as a specifier of a high-risk subtype of CD (Blair et al., 2014; Frick \& White, 2008), we surmised that profiles would differ on this variable (i.e., defining a high-CU and lowCU groups). Similarly, previous work has defined a subgroup of youth who meet criteria for CD and also exhibit high levels of internalizing psychopathology (Polier et al., 2012). Therefore, we predicted that youth would differ on trait indices related to emotional distress and anxiety (i.e., a group high in emotional urgency and enhanced response to punishment).

Based on work examining patterns of psychopathology in emerging adolescence (Brislin et al., 2020), we predicted that CD+ youth would exhibit high levels of both a general liability for broad 
psychopathology and variance specific to externalizing disorders. We also predicted that these indicators would differ as a function of personality profile, specifically with individuals with a high distress personality profile also scoring high on a broad liability for psychopathology, while a group marked by high levels of CU traits would display greater externalizing psychopathology. Given the exploratory nature of these analyses we did not have strong a priori hypotheses regarding differences in social, environmental, and neurocognitive factors by profiles.

\section{Methods}

\section{Participants}

The present study used data collected from youth and parents from the ABCD study, a largescale study of youth aged 9 to 10 years $(N=11,875)$, recruited from 21 research sites across the United States (Barch et al., 2018; Garavan et al., 2018; Volkow et al., 2018). These data were collected from baseline visits between September 1, 2016 and November 15, 2018 (ABCD Release 2.01, DOI: 10.15154/1504041). We removed 323 participants from the analyses owing to nonresponse on the Kiddie-Structured Assessment for Affective Disorders and Schizophrenia for DSM-5 (KSADS), which was used to determine CD diagnosis, or grouping variables (UPPS, Behavioral Inhibition System/Behavioral Activation System [BIS/BAS], CU traits), leaving a final sample size of 11,552 individuals, with 365 youth meeting criteria for CD. The participants with available data did not differ significantly from the full sample on key demographic variables (sex, race/ethnicity, household income, parental education, and marital status). Institutional review board approval was obtained before data collection. All parents provided written informed consent and all children provided assent.

The sample of 11,552 was roughly gender balanced (45.3\% female) with a mean age of 9.92 years $(S D=0.62$ years $)$. Around half $(49.6 \%)$ of the sample was white, with the remaining participants identifying themselves as Hispanic (19.0\%), Black (14.2\%), or Other/Multi-racial (10.4\%). Approximately two-thirds of youth (64\%) came from households in which the parents were married. 
Most parents $(85.7 \%)$ reported an education level of at least some college, and most households reported an annual income of at least $\$ 50,000(61.3 \%)$.

\section{Measures}

Measures used in the study are described briefly below; however, please refer to the following papers for a more detailed description of the measures used in this study and their psychometric performance in the ABCD sample: personality and mental health (Barch et al., 2018); culture and environment (Zucker et al., 2018); neurocognition (Luciana et al., 2018).

\section{Selection Variable}

The KSADS-5 is a structured, diagnostic interview that was administered to parents via computer in reference to their child (Kobak et al., 2013). Parents completed all modules of the KSADS5 with the exception of the enuresis, encopresis, and selective mutism modules (Barch et al., 2018). For the purposes of the current study, participants were placed in the CD-positive (CD+) group if they met past or present criteria for CD at the time of the baseline assessment (age 9-10; e.g., childhood onset; $n$ $=365)$.

\section{Grouping Variables}

A 20-item youth short-version of the UPPS-P, developed for use in the ABCD study (Barch et al., 2018), was administered via self-report at baseline to index trait impulsivity. The UPPS-P has five subscales: Negative Urgency, Positive Urgency, Lack of Perseverance, Lack of Planning, and Sensation Seeking.

The BIS/BAS measure (Barch et al., 2018; Pagliaccio et al., 2016) is a 24-item youth-report scale designed to assess three facets of behavioral activation (BAS): Drive (intensity of goal directed behavior), Fun Seeking (spontaneity), and Reward Responsiveness (excitement over reinforcing outcomes), as well as a Behavioral Inhibition (BIS) scale, comprised of items tapping worry and fearfulness, with scores related to sensitivity to punishment as well as avoidance motivation. 
A four-item youth-report measure of $C U$ traits was developed to index lack of empathic concern, shallow affect, and low moral regulation within the ABCD study (Hawes et al., 2019). This measure of CU traits was derived from three items (reversed) from the Strengths and Difficulties Questionnaire (SDQ; Goodman, 1997) and one item from the Child Behavior Checklist (CBCL; Achenbach et al., 2000). Scores were computed using a traditional summed score approach. This brief scale demonstrated adequate convergent and discriminant validity both in a subsample of the ABCD study as well as in separate validation samples (Hawes et al., 2019).

\section{Criterion Variables: Family History}

Family history of substance problems was computed from ABCD's Family History Assessment (Barch et al., 2018). A threshold was established for a family member counting as an "affected case" based on the number of serious problems that person has had due to alcohol use and substance use. The following coding was used: $0=$ neither parent met the threshold; $1=$ at least one parent met threshold.

Family history of psychopathology was computed based on previously published protocols

(Milne et al., 2008; Milne et al., 2009). A family history composite score was constructed from responses for ABCD’s Family History Assessment (Barch et al., 2018). Responses for the eight categories of psychopathology problems (e.g., depression, mania, ever psychiatrically hospitalized) were tabulated separately for first-degree relatives (mother, father, full siblings) and second-degree relatives (i.e., everyone else including aunts and uncles, grandparents, etc.). A weighted sum score was computed as follows: first degree cases $+0.5 *$ second degree cases. This number was then divided by the total possible score for the given subject, given the relations present in their own family tree. These proportion scores were calculated for each category (e.g., depression) and then summed across categories.

\section{Criterion Variables: Dimensional Measures of Psychopathology}

The $C B C L$ (age 6 to 18 form; Achenbach et al., 2000) is a 119-item parent-report on child psychopathology. A general psychopathology (P-factor; Caspi et al., 2014; Caspi \& Moffitt, 2018) and 
orthogonal externalizing (EXT) and internalizing (INT) factors were modeled, and factor scores were used in subsequent analyses. Factor scores were derived by fitting a bifactor model to 8 CBCL scales (Withdrawn, Somatic Complaints, Anxious/Depressed, Social Problems, Thought Problems, Attention Problems, Delinquent Behavior, and Aggressive Behavior; Clark et al., 2020). In this model there was a general $\mathrm{P}$ factor that all scales loaded onto (average scale loading on $\mathrm{P}=.69$ ), and two specific factors: EXT and INT (average scale loading on sub-factors $=.43$ ). The EXT specific factor included the Delinquent and Aggressive Behaviors scales, while the INT specific factor included the Withdrawn, Somatic Complaints, and Anxious/Depressed scales. This model fit well based on conventional fit thresholds $\left(\chi^{2}=747.73, \mathrm{df}=16, p<.001 ; \mathrm{RMSEA}=.062 ; \mathrm{CFI}=.985 ; \mathrm{TLI}=.974 ; \mathrm{SRMR}=.015\right)$ and was chosen for its good model fit and theoretical interpretability (Clark et al., 2020). For additional information regarding modeling please refer to (Clark et al., 2020). Associations with the traditional CBCL scales were also included for comparison (see Supplemental Table 1).

\section{Criterion Variables: Social Environment}

Youth reported on School Risk and Protective Factors (SRPF) to assess their connection to the school environment (Zucker et al., 2018). This 12-item measure was derived from the PhenX Toolkit, yielding three subscales: a six-item School Environment scale, a four-item School Involvement scale, and a two-item School Disengagement scale.

Both parents and children reported on neighborhood safety and crime, with items from the PhenX Toolkit (Zucker et al., 2018). Parents responded to three statements regarding feelings of safety and presence of crime in their neighborhood, rated on a five-point Likert scale. Youth responded to only one item ("My neighborhood is safe from crime"), rated on the same 5-point Likert scale.

\section{Criterion Variables: Social Functioning}

Parent and child both rated the quality of family environment with the Family Conflict subscale from the Family Environment Scale (Zucker et al., 2018). This 9-item measure from the PhenX Toolkit has a binary (true/false) response format to items related to presence of family conflict. 
Youth reported on their perceived level of parental monitoring via the Parental Monitoring Survey, a five-item scale that was developed to assess parents efforts to keep track of their child's whereabouts at home as well as outside of the home (Zucker et al., 2018).

Parents reported on their child's prosocial behavior using the Prosocial Behavior Scale, which is a three-item scale formed from the SDQ (Goodman, 2001). Youth also responded; however, these three items were used in part to compute the 4-item CU Traits scale and were therefore not evaluated as a criterion variable.

\section{Criterion Variables: Neurocognition}

General Cognitive Ability (GCA) scores were computed by fitting a bifactor model to behavioral tasks from the NIH toolbox, the Rey Auditory Verbal Learning Task, the WISC-V, and the "Little Man" task (Sripada et al., 2019). GCA factor scores were generated using expected a posteriori scoring (MacCallum, 2009).

\section{Data Analyses}

We first examined whether youth with $(n=365)$ versus without $(n=11,187)$ a CD diagnosis differed in demographic characteristics, personality traits, presence of comorbid psychopathology, or social environment characteristics. These analyses were conducted in SPSS (Version 25) and analyzed using data nested by site and family. Given the large sample size used for these analyses, effect sizes are also reported alongside the use of a strict significance threshold $(p<0.005)$ to increase interpretability of results. Then, in Mplus (version 8.4; Muthén \& Muthén, 2017), we used LPA to identify mutually exclusive, latent subgroups of youth. Each of the 10 grouping variables (i.e., Positive Urgency, Negative Urgency, Lack of Planning, Lack of Perseverance, Sensation Seeking, BIS, BAS-Reward Responsivity, BAS-Drive, BAS-Fun Seeking, and CU traits) were input as profile indicators. We used the two-level, complex mixture analysis type in Mplus in order to account for clustering by study site and family identifiers. We tested four different LPA models using a step-wise approach, beginning with a oneprofile model (see Table 4). We used empirical indicators to inform our selection of the best fitting 
model: lower Akaike's Information Criterion (AIC)/Bayesian Information Criterion (BIC) values; 2) entropy closer to 1.00; and 3) non-significant Lo-Mendell-Rubin test. We then used class interpretability to determine the final model. As described in the literature, additional classes may show an improvement via empirical indicators but are not meaningful in relation to observable group differences (Collins \& Lanza, 2010).

Follow-up analyses examining latent profile differences on continuous outcome variables were performed in Mplus using the Bolck, Croon, and Hagenaars (BCH) method (Asparouhov \& Muthén, 2014). The BCH method allows for the examination of continuous outcome variables while accounting for unequal variance among the outcome variables and measurement error of the latent profile using probabilities accounts (Bauer \& Shanahan, 2007). To examine differences between profiles on demographic variables, latent profile information was exported into SPSS (Version 25) and analyzed using chi-square difference tests in data nested by site and family. Given the relatively high number of omnibus and between-group analyses conducted, to minimize Type I error, the statistical significance threshold was $p<.005$.

\section{Results}

\section{Characteristics of youth with childhood-onset conduct disorder}

Demographic characteristics for youth with (CD+) and without (CD-) a CD diagnosis are presented in Table 1 . As expected, these groups differed in composition by sex $(\varphi=-0.07)$, race/ethnicity (Cramer's $V=0.08)$, family income $(V=0.07)$, parental marital status $(V=0.08)$, highest parental education $(V=0.07)$, and family history of substance problems $(\varphi=0.10)$. The $C D+$ group had a higher proportion of males and Black and other/multiracial youth, and were more likely to: 1) come from a lower income household, 2) have an unmarried parent, 3) have a lower rate of parents with at least a Bachelor's degree, and 4) have a higher incidence rate of at least one parent having a substance use problem. The two groups did not differ significantly based on family history of psychopathology. 
Regarding personality variables (Table 2), the CD+ group had significantly higher scores on all of the UPPS subscales as hypothesized (Cohen's $d$ 's ranged from 0.41 for Negative Urgency to 0.15 for Sensation Seeking). The CD+ and CD-groups did not differ on BIS or on the BAS-Reward Response subscale; however, the CD+ group did score significantly higher on the BAS-Drive $(d=0.36)$, BAS-Fun Seeking $(d=0.37)$, and CU Traits $(d=0.73)$ scales. The CD+ group also scored higher on levels of broad psychopathology $(d=1.82)$ and $\operatorname{EXT}(d=1.96)$ and there was a trend towards lower scores on the INT subfactor $(d=-0.22 ; p=.009)$ in the $\mathrm{CD}+$ group (Table 3$)$. Youth in the CD+ group reported significantly lower scores on the School Environment scale $(d=-0.22$; Table 3$)$, reflecting less educational resources, as well as significantly higher on the School Disengagement scale $(d=0.20)$. Both youth $(d=-0.33)$ and parents $(d=-0.27)$ in the CD+ group reported living in significantly less safe neighborhoods and had higher levels of family conflict ( $d$ youth $=0.40 ; d$ parent $=0.84$ ). Youth in the $\mathrm{CD}+$ group also reported having less parental monitoring $(d=-0.26)$, and their parents reported they exhibited less prosocial behavior in comparison to youth in the CD-group $(d=-1.05)$. Lastly, regarding neurocognitive functioning, youth in the CD+ group scored significantly lower on the GCA index $(d=-$ $0.46)$.

\section{Trait profiles of youth with childhood-onset conduct disorder}

Next, different patterns of trait impulsivity, inhibition, behavioral activation, and callousness were examined to account for heterogeneity within the CD+ group. Model fit and entropy statistics are presented in Table 4. The three-profile solution provided the best classification certainty via the highest entropy, and while the AIC and BIC improved slightly when defining a four-profile solution, the LoMendell-Rubin test provided evidence that there was not a significant improvement in moving from a three- to four-profile model. The three-profile solution was deemed to be substantively interpretable and therefore was retained for further analyses.

The trait profile of the three-profile solution is depicted in Figure 1, and the trait values and results of difference tests are presented in Table 2. Profile $1(n=131)$ had the lowest scores on the 
Negative Urgency, Positive Urgency, Sensation Seeking, BIS, and BAS scales, and scored moderately

high on Lack of Planning, Lack of Perseverance, and CU traits, defining a low impulsivity/BAS group. Profile $2(n=190)$ scored moderately high on Negative Urgency, Positive Urgency, BIS, and BAS scales, and lowest on Lack of Planning, Lack of Perseverance, and CU traits, defining a high Urgency/BAS group. Lastly, Profile $3(n=44)$ had the highest scores on all UPPS subscales, excluding Sensation Seeking, did not differ significantly from Profile 2 on BIS/BAS scale scores, and had the highest score on CU traits, defining a global high severity group.

\section{Characteristics of trait profiles}

Demographic characteristics for the trait profiles are presented in Table 1. No significant differences between profiles were observed for any of the demographic variables. Profile differences in psychopathology, social environment, and neurocognition are presented in Table 3. Youth in Profile 3 (global high severity) were significantly higher than those in Profile 1 (low impulsivity/BAS) on P and EXT factor scores, while Profile 2 (high Urgency/BAS) was significantly higher than Profile 1 on EXT scores only (Table 3, Figure 2). The groups did not differ significantly on INT factor scores. Youth in Profile 2 reported significantly better school environment and higher rates of school involvement, and the lowest rates of school disengagement. The youth in Profile 3 reported rates of family conflict that were significantly higher than individuals in Profile 1 and 2; however, this finding was not consistent in the parent report of family conflict, where none of the profiles differed significantly. The profiles did not differ significantly on level of parental monitoring or parent report of prosocial behavior. Regarding neurocognition, the three profile types also did not differ significantly from each other.

\section{Discussion}

The current study used person-centered analyses to characterize heterogeneity on multiple trait dimensions of youth who met criteria for childhood-onset CD. As expected, and consistent with previous studies on childhood-onset CD (Moffitt, 1993; Moffitt et al., 2002; Nock et al., 2006), youth who met criteria for $\mathrm{CD}$ were higher on trait measures of impulsivity, behavioral activation subscales, 
and CU traits. Of note, these youth did not differ from the CD-group on sensitivity to punishment (BIS) and the BAS-Reward Responsivity subscale. While these subscales proved informative for defining latent profiles, this heterogeneity is lost when examining differences between the CD+ versus CDyouth. As scores on these subscales have been linked to differences in neural and psychophysiological response (Arnett, 1997; Kim et al., 2015; Simon et al., 2010), these findings demonstrate a strength of the study: the characterization of meaningful groups that would not otherwise emerge when simply examining groups defined by the DSM-5 criteria. CD+ youth also scored significantly higher on an aggregate liability for broad psychopathology and externalizing psychopathology with a trend-level lower scores on liability for internalizing psychopathology, consistent with previous research on the nomological networks of the psychopathology factors (Brislin et al., 2020). In addition, the CD+ youth had significant environmental, social, and neurocognitive impairments.

We were also able to define meaningful profiles based on differing personality trait scores within the CD+ group, further accounting for heterogeneity within this high-risk group. The LPA identified three personality profiles that were generally consistent with our hypotheses. For example, while Profiles 1 and 3 included youth who scored relatively high on CU traits, they differed on trait impulsivity, suggesting that although these two traits can co-occur, they represent distinct mechanistic dimensions relevant to CD symptoms. In addition, the youth who scored lower on CU traits (Profile 2) also had the highest scores on BIS, reflecting a sensitivity to punishment that is thought to be reduced in individuals high on CU traits (Byrd et al., 2018; Fairchild et al., 2008; Fonseca \& Yule, 1995; Morgan et al., 2014; Syngelaki et al., 2013). Furthermore, Profiles 1 and 3 significantly differed on emotional impulsivity, with one group scoring in a normative range on Negative and Positive Urgency (Profile 1) and the other group scoring approximately one standard deviation higher than the full sample $(N=$ 11,552; Profile 3).

These profiles also defined groups that differed significantly on clinically relevant variables. The P factor is conceptualized as a broad liability for all forms of prevalent psychiatric symptomatology, 
while the EXT and INT factors represent more of a domain-specific liability (Brislin et al., 2020; Lahey et al., 2012, 2015). Therefore, different factor scores on P and EXT for the different profiles suggests that these latent profiles provide meaningful information regarding risk for psychopathology. For example, individuals in Profile 3 scored significantly higher on both the P factor and the EXT subfactor (in comparison to Profile 1) consistent with the characterization of a high global severity group. This suggests that these youth are exhibiting psychopathology beyond CD and may also be at risk for displaying this pattern of broad psychological distress as they develop. In comparison, youth in Profile 2 scored significantly higher only on EXT compared to Profile 1, suggesting that this personality profile is selectively predictive of risk for externalizing, but not general psychopathology. Future work to better characterize the patterns of comorbidity of these profiles is needed to determine the stability of these associations, as well as to examine associations with psychopathology that typically has an onset in adolescence (i.e., substance use disorders), and therefore cannot be reliably studied at this age in a community sample.

The groups defined by the latent profiles also differed on some environmental and social variables. Youth in Profile 2 had significantly higher levels of school enrichment and involvement than those in Profiles 1 and 3 and were less disengaged in school compared to the youth in Profile 3. In addition, Profile 3 youth reported significantly higher levels of family conflict than those in Profiles 1 and 3. These findings are of interest as the youth in Profile 1 appear to be relatively low risk-they have the lowest scores on the P and EXT factors, are only elevated on CU traits, and score in a relatively normative range (within +/- 0.50 standard deviation of the full sample) on impulsivity and responsivity to punishment and reward. Further research is needed to determine the developmental trajectory of these youth as, based on the current cluster of risk/protective factors, we would hypothesize that CD symptoms in this group is likely to remit over time.

One limitation, the diagnostic instrument (KSADS) was completed by a parent and not a trained clinician. Despite this, symptoms of CD are highly behavioral and observable. Therefore, a parent-rating 
is likely to be valid. In support of this, youth with CD diagnoses scored significantly higher on CBCL Externalizing Problems and the Conduct Problems scale (Supplemental Table 1) providing convergent evidence for the validity of the measure. Future waves of data collection of the ABCD study will include youth self-report of DSM-5 symptoms, which can be used for further validation of the profiles identified in this study.

These results are valuable for understanding antisocial behavior in youth and how different configurations of personality traits can provide clinically relevant information to further understand heterogeneity within the childhood-onset CD diagnosis. For example, youth within Profile 3 were elevated on CU trait as well as trait indices of distress (Negative/Positive Urgency) and behavioral activation. These youth might therefore benefit from treatments focused on regulating emotions, increasing prosocial behavior, and implementing behavioral interventions to increase planfulness. In comparison, the youth in Profile 1 also scored relatively high on CU traits and therefore would likely benefit from interventions to increase prosocial behavior but would not need additional interventions targeting distress and impulsivity.

In addition, these findings provide information regarding how these mechanistic dimensions interact to form distinct profiles within youth diagnosed with childhood-onset CD. While impulsivity, punishment and reward responsivity, and CU traits have each been studied as unique risk factors for antisocial behavior, this is the first study to examine how these risk factors co-occur. As these systems rely on shared neural architecture (e.g., amygdala response is linked to both reward responsivity and CU traits; Blair et al., 2014; Byrd et al., 2014; Oldham et al., 2018)), a nuanced understanding of how these traits co-occur may help to clarify our understanding of individual differences in neural response of youth who demonstrate early antisocial behavior. Future research with the goal of replicating these profiles in additional datasets and across development is needed to determine the generalizability and stability of these patterns. Although the data used in this study are cross-sectional, data collection in the ABCD study is ongoing, and these findings therefore set the stage for prospective longitudinal research 
using multimodal data—-such as neuroimaging and parent- and teacher-reports - to more fully determine how these latent profiles account for the course, severity, and comorbidity of psychopathology in these groups of high-risk youth. 


\section{References}

Achenbach, T. M., Ruffle, T. M., \& others. (2000). The Child Behavior Checklist and related forms for assessing behavioral/emotional problems and competencies. Pediatrics in Review, 21(8), 265271.

American Psychiatric Association. (2013). Diagnostic and statistical manual of mental disorders (DSM5®). American Psychiatric Pub.

Arnett, P. A. (1997). Autonomic responsivity in psychopaths: A critical review and theoretical proposal. Clinical Psychological Review, 903-936.

Asparouhov, T., \& Muthén, B. (2014). Auxiliary variables in mixture modeling: Using the BCH method in Mplus to estimate a distal outcome model and an arbitrary secondary model. Mplus Web Notes, 21(2), 1-22.

Barch, D. M., Albaugh, M. D., Avenevoli, S., Chang, L., Clark, D. B., Glantz, M. D., Hudziak, J. J., Jernigan, T. L., Tapert, S. F., Yurgelun-Todd, D., Alia-Klein, N., Potter, A. S., Paulus, M. P., Prouty, D., Zucker, R. A., \& Sher, K. J. (2018). Demographic, physical and mental health assessments in the adolescent brain and cognitive development study: Rationale and description. Developmental Cognitive Neuroscience, 32, 55-66. https://doi.org/10.1016/j.dcn.2017.10.010

Bauer, D. J., \& Shanahan, M. J. (2007). Modeling complex interactions: Person-centered and variablecentered approaches. Modeling Contextual Effects in Longitudinal Studies, 255-283.

Beauchaine, T. P., Hinshaw, S. P., \& Pang, K. L. (2010). Comorbidity of attention-deficit/hyperactivity disorder and early-onset conduct disorder: Biological, environmental, and developmental mechanisms. Clinical Psychology: Science and Practice, 17(4), 327-336.

Blair, R. J. R., Leibenluft, E., Pine, D. S., Frick, P. J., Ray, J. V., Thornton, L. C., \& Kahn, R. E. (2014). Can callous-unemotional traits enhance the understanding, diagnosis, and treatment of serious conduct problems in children and adolescents? A comprehensive review. New England Journal of Medicine, 140(1), 1. 
Brislin, S., Martz, M. E., Joshi, S., Duval, E. R., Gard, A. M., Clark, D. A., Hyde, L. W., Hicks, B. M., Angstadt, M., Rutherford, S., \& al, et. (2020). Differentiated Nomological Networks of Internalizing, Externalizing, and the General Factor of Psychopathology ("P factor") in Emerging Adolescence in the ABCD study. PsyArXiv. https://doi.org/10.31234/osf.io/d6htz

Byrd, A. L., Hawes, S. W., Burke, J. D., Loeber, R., \& Pardini, D. A. (2018). Boys with conduct problems and callous-unemotional traits: Neural response to reward and punishment and associations with treatment response. Developmental Cognitive Neuroscience, 30, 51-59.

Byrd, A. L., Loeber, R., \& Pardini, D. A. (2014). Antisocial Behavior, Psychopathic Features and Abnormalities in Reward and Punishment Processing in Youth. Clinical Child and Family Psychology Review, 17(2), 125-156. https://doi.org/10.1007/s10567-013-0159-6

Caspi, A., Houts, R. M., Belsky, D. W., Goldman-Mellor, S. J., Harrington, H., Israel, S., Meier, M. H., Ramrakha, S., Shalev, I., Poulton, R., \& others. (2014). The p factor: One general psychopathology factor in the structure of psychiatric disorders? Clinical Psychological Science, 2(2), 119-137.

Caspi, A., \& Moffitt, T. E. (2018). All for one and one for all: Mental disorders in one dimension. American Journal of Psychiatry, 175(9), 831-844.

Clark, D. A., Hicks, B. M., Angstadt, M., Rutherford, S., Taxali, A., Hyde, L. W., Weigard, A. S., Heitzeg, M., \& Sripada, C. (2020). The General Factor of Psychopathology in the Adolescent Brain Cognitive Development (ABCD) Study: A Comparison of Alternative Modeling Approaches. https://doi.org/10.31234/osf.io/b6uy7

Colledge, E., \& Blair, R. (2001). The relationship in children between the inattention and impulsivity components of attention deficit and hyperactivity disorder and psychopathic tendencies. Personality and Individual Differences, 30(7), 1175-1187.

Collins, L. M., \& Lanza, S. T. (2010). Latent class and latent transition analysis: With applications in the social, behavioral, and health sciences (Vol. 718). John Wiley \& Sons. 
Connor, D. F., Ford, J. D., Albert, D. B., \& Doerfler, L. A. (2007). Conduct disorder subtype and comorbidity. Annals of Clinical Psychiatry, 19(3), 161-168.

Fairchild, G., Hawes, D. J., Frick, P. J., Copeland, W. E., Odgers, C. L., Franke, B., Freitag, C. M., \& De Brito, S. A. (2019). Conduct disorder. Nature Reviews Disease Primers, 5(1), 1-25. https://doi.org/10.1038/s41572-019-0095-y

Fairchild, G., van Goozen, S. H. M., Stollery, S. J., Aitken, M. R. F., Savage, J., Moore, S. C., \& Goodyer, I. M. (2009). Decision Making and Executive Function in Male Adolescents with Early-Onset or Adolescence-Onset Conduct Disorder and Control Subjects. Biological Psychiatry, 66(2), 162-168. https://doi.org/10.1016/j.biopsych.2009.02.024

Fairchild, G., Van Goozen, S. H., Stollery, S. J., \& Goodyer, I. M. (2008). Fear conditioning and affective modulation of the startle reflex in male adolescents with early-onset or adolescenceonset conduct disorder and healthy control subjects. Biological Psychiatry, 63(3), 279-285.

Fanti, K. A., Kyranides, M. N., Lordos, A., Colins, O. F., \& Andershed, H. (2018). Unique and interactive associations of callous-unemotional traits, impulsivity and grandiosity with child and adolescent conduct disorder symptoms. Journal of Psychopathology and Behavioral Assessment, $40(1), 40-49$.

Fonseca, A., \& Yule, W. (1995). Personality and antisocial behavior in children and adolescents: An enquiry into Eysenck's and Gray's theories. Journal of Abnormal Child Psychology, 23(6), 767781.

Frick, P. J. (2012). Developmental pathways to conduct disorder: Implications for future directions in research, assessment, and treatment. Journal of Clinical Child \& Adolescent Psychology, 41(3), $378-389$.

Frick, P. J., \& Dickens, C. (2006). Current perspectives on conduct disorder. Current Psychiatry Reports, 8(1), 59-72. 
Frick, P. J., Ray, J. V., Thornton, L. C., \& Kahn, R. E. (2014). Annual research review: A developmental psychopathology approach to understanding callous-unemotional traits in children and adolescents with serious conduct problems. Journal of Child Psychology and Psychiatry, 55(6), 532-548.

Frick, P. J., \& White, S. F. (2008). Research review: The importance of callous-unemotional traits for developmental models of aggressive and antisocial behavior. Journal of Child Psychology and Psychiatry, 49(4), 359-375.

Garavan, H., Bartsch, H., Conway, K., Decastro, A., Goldstein, R. Z., Heeringa, S., Jernigan, T., Potter, A., Thompson, W., \& Zahs, D. (2018). Recruiting the ABCD sample: Design considerations and procedures. Developmental Cognitive Neuroscience, 32, 16-22. https://doi.org/10.1016/j.dcn.2018.04.004

Goodman, R. (1997). The Strengths and Difficulties Questionnaire: A research note. Journal of Child Psychology and Psychiatry, 38(5), 581-586.

Goodman, R. (2001). Psychometric properties of the strengths and difficulties questionnaire. Journal of the American Academy of Child \& Adolescent Psychiatry, 40(11), 1337-1345.

Haas, S. M., Derefinko, K. J., \& Waschbusch, D. A. (2017). The use of multimethod impulsivity assessment in the prediction of ADHD, conduct problems, and callous-unemotional symptoms. Personality and Individual Differences, 116, 289-295.

Hawes, S. W., Waller, R., Thompson, W. K., Hyde, L. W., Byrd, A. L., Burt, S. A., Klump, K. L., \& Gonzalez, R. (2019). Assessing callous-unemotional traits: Development of a brief, reliable measure in a large and diverse sample of preadolescent youth. Psychological Medicine, 50(3), 456-464.

Kim, S. H., Yoon, H., Kim, H., \& Hamann, S. (2015). Individual differences in sensitivity to reward and punishment and neural activity during reward and avoidance learning. Social Cognitive and Affective Neuroscience, 10(9), 1219-1227. 
Kobak, K. A., Kratochvil, C., Stanger, C., \& Kaufman, J. (2013). Computerized screening of comorbidity in adolescents with substance or psychiatric disorders. Anxiety Disorders and Depression.(La Jolaa, CA).

Lahey, B. B., Applegate, B., Hakes, J. K., Zald, D. H., Hariri, A. R., \& Rathouz, P. J. (2012). Is there a general factor of prevalent psychopathology during adulthood? Journal of Abnormal Psychology, 121(4), 971.

Lahey, B. B., \& Loeber, R. (1994). Framework for a developmental model of oppositional defiant disorder and conduct disorder. In Disruptive behavior disorders in childhood (pp. 139-180). Springer.

Lahey, B. B., Rathouz, P. J., Keenan, K., Stepp, S. D., Loeber, R., \& Hipwell, A. E. (2015). Criterion validity of the general factor of psychopathology in a prospective study of girls. Journal of Child Psychology and Psychiatry, 56(4), 415-422. https://doi.org/10.1111/jcpp.12300

Longman, T., Hawes, D. J., \& Kohlhoff, J. (2016). Callous-unemotional traits as markers for conduct problem severity in early childhood: A meta-analysis. Child Psychiatry \& Human Development, 47(2), 326-334.

Luciana, M., Bjork, J., Nagel, B., Barch, D., Gonzalez, R., Nixon, S., \& Banich, M. (2018). Adolescent neurocognitive development and impacts of substance use: Overview of the adolescent brain cognitive development (ABCD) baseline neurocognition battery. Developmental Cognitive Neuroscience, 32, 67-79.

MacCallum, R. C. (2009). Factor Analysis. In R. Millsap \& A. Maydeu-Olivares, The SAGE Handbook of Quantitative Methods in Psychology (pp. 123-147). SAGE Publications Ltd. https://doi.org/10.4135/9780857020994.n6

McMahon, R. J., Witkiewitz, K., Kotler, J. S., \& Conduct Problems Prevention Research Group. (2010). Predictive validity of callous-unemotional traits measured in early adolescence with respect to 
multiple antisocial outcomes. Journal of Abnormal Psychology, 119(4), 752-763. https://doi.org/10.1037/a0020796

Milne, B. J., Caspi, A., Harrington, H., Poulton, R., Rutter, M., \& Moffitt, T. E. (2009). Predictive value of family history on severity of illness: The case for depression, anxiety, alcohol dependence, and drug dependence. Archives of General Psychiatry, 66(7), 738-747.

Milne, B., Moffitt, T., Crump, R., Poulton, R., Rutter, M., Sears, M., Taylor, A., \& Caspi, A. (2008). How should we construct psychiatric family history scores? A comparison of alternative approaches from the Dunedin Family Health History Study. Psychological Medicine, 38(12), 1793-1802.

Moffitt, T. E. (1993). Adolescence-limited and life-course-persistent antisocial behavior: A developmental taxonomy. Psychological Review, 100(4), 674.

Moffitt, T. E., Caspi, A., Harrington, H., \& Milne, B. J. (2002). Males on the life-course-persistent and adolescence-limited antisocial pathways: Follow-up at age 26 years. Development and Psychopathology, 14(1), 179-207. https://doi.org/10.1017/s0954579402001104

Moffitt, T. E., order, in alphabetical, Arseneault, L., Jaffee, S. R., Kim-Cohen, J., Koenen, K. C., Odgers, C. L., Slutske, W. S., \& Viding, E. (2008). Research review: DSM-V conduct disorder: Research needs for an evidence base. Journal of Child Psychology and Psychiatry, 49(1), 3-33.

Morgan, J. E., Bowen, K. L., Moore, S. C., \& Van Goozen, S. H. (2014). The relationship between reward and punishment sensitivity and antisocial behavior in male adolescents. Personality and Individual Differences, 63, 122-127.

Muthén, L. K., \& Muthén, B. O. (2018). Mplus user’s guide (8th ed.). Muthén \& Muthén.

Nock, M. K., Kazdin, A. E., Hiripi, E., \& Kessler, R. C. (2006). Prevalence, Subtypes, and Correlates of DSM-IV Conduct Disorder in the National Comorbidity Survey Replication. Psychological Medicine, 36(5), 699-710. https://doi.org/10.1017/S0033291706007082 
Odgers, C. L., Moffitt, T. E., Broadbent, J. M., Dickson, N., Hancox, R. J., Harrington, H., Poulton, R., Sears, M. R., Thomson, W. M., \& Caspi, A. (2008). Female and male antisocial trajectories: From childhood origins to adult outcomes. Development and Psychopathology, 20(2), 673-716. https://doi.org/10.1017/S0954579408000333

Oldham, S., Murawski, C., Fornito, A., Youssef, G., Yücel, M., \& Lorenzetti, V. (2018). The anticipation and outcome phases of reward and loss processing: A neuroimaging meta-analysis of the monetary incentive delay task. Human Brain Mapping, 39(8), 3398-3418.

Pagliaccio, D., Luking, K. R., Anokhin, A. P., Gotlib, I. H., Hayden, E. P., Olino, T. M., Peng, C.-Z., Hajcak, G., \& Barch, D. M. (2016). Revising the BIS/BAS Scale to study development: Measurement invariance and normative effects of age and sex from childhood through adulthood. Psychological Assessment, 28(4), 429.

Pardini, D. A., \& Fite, P. J. (2010). Symptoms of conduct disorder, oppositional defiant disorder, attention-deficit/hyperactivity disorder, and callous-unemotional traits as unique predictors of psychosocial maladjustment in boys: Advancing an evidence base for DSM-V. Journal of the American Academy of Child and Adolescent Psychiatry, 49(11), 1134-1144. https://doi.org/10.1016/j.jaac.2010.07.010

Pardini, D., Obradovic, J., \& Loeber, R. (2006). Interpersonal callousness, hyperactivity/impulsivity, inattention, and conduct problems as precursors to delinquency persistence in boys: A comparison of three grade-based cohorts. Journal of Clinical Child and Adolescent Psychology, $35(1), 46-59$.

Patrick, C. J., \& Drislane, L. E. (2015). Triarchic model of psychopathy: Origins, operationalizations, and observed linkages with personality and general psychopathology. Journal of Personality, $83(6), 627-643$.

Peugh, J., \& Fan, X. (2013). Modeling unobserved heterogeneity using latent profile analysis: A Monte Carlo simulation. Structural Equation Modeling: A Multidisciplinary Journal, 20(4), 616-639. 
Platje, E., Huijbregts, S. C., van Goozen, S. H., Popma, A., Cima, M., \& Swaab, H. J. (2018). Executive functioning, reward/punishment sensitivity, and conduct problems in boys with callousunemotional traits. International Journal of Offender Therapy and Comparative Criminology, 62(13), 4008-4023.

Polier, G. G., Vloet, T. D., Herpertz-Dahlmann, B., Laurens, K. R., \& Hodgins, S. (2012). Comorbidity of conduct disorder symptoms and internalising problems in children: Investigating a community and a clinical sample. European Child \& Adolescent Psychiatry, 21(1), 31-38.

Ross, S. R., Molto, J., Poy, R., Segarra, P., Pastor, M. C., \& Montanés, S. (2007). Gray’s model and psychopathy: BIS but not BAS differentiates primary from secondary psychopathy in noninstitutionalized young adults. Personality and Individual Differences, 43(7), 1644-1655.

Rowe, R., Maughan, B., Moran, P., Ford, T., Briskman, J., \& Goodman, R. (2010). The role of callous and unemotional traits in the diagnosis of conduct disorder. Journal of Child Psychology and Psychiatry, 51(6), 688-695.

Sica, C., Ciucci, E., Baroncelli, A., Frick, P. J., \& Patrick, C. J. (2019). Not just for adults: Using the triarchic model of psychopathy to inform developmental models of conduct problems in adolescence. Journal of Clinical Child \& Adolescent Psychology, 1-15.

Silberg, J., Moore, A. A., \& Rutter, M. (2015). Age of onset and the subclassification of conduct/dissocial disorder. Journal of Child Psychology and Psychiatry, 56(7), 826-833. https://doi.org/10.1111/jcpp.12353

Simon, J. J., Walther, S., Fiebach, C. J., Friederich, H.-C., Stippich, C., Weisbrod, M., \& Kaiser, S. (2010). Neural reward processing is modulated by approach-and avoidance-related personality traits. Neuroimage, 49(2), 1868-1874.

Snyder, J., Prichard, J., Schrepferman, L., Patrick, M. R., \& Stoolmiller, M. (2004). Child impulsiveness - Inattention, early peer experiences, and the development of early onset conduct problems. Journal of Abnormal Child Psychology, 32(6), 579-594. 
Sripada, C., Angstadt, M., Rutherford, S., \& Taxali, A. (2019). Brain Network Mechanisms of General Intelligence. BioRxiv, 657205. https://doi.org/10.1101/657205

Syngelaki, E. M., Fairchild, G., Moore, S. C., Savage, J. C., \& van Goozen, S. H. (2013). Affective startle potentiation in juvenile offenders: The role of conduct problems and psychopathic traits. Social Neuroscience, 8(2), 112-121.

Urben, S., Habersaat, S., Pihet, S., Suter, M., de Ridder, J., \& Stéphan, P. (2018). Specific contributions of age of onset, callous-unemotional traits and impulsivity to reactive and proactive aggression in youths with conduct disorders. Psychiatric Quarterly, 89(1), 1-10.

Venables, N., Hall, J., \& Patrick, C. (2014). Differentiating psychopathy from antisocial personality disorder: A triarchic model perspective. Psychological Medicine, 44(5), 1005-1013.

Volkow, N. D., Koob, G. F., Croyle, R. T., Bianchi, D. W., Gordon, J. A., Koroshetz, W. J., PérezStable, E. J., Riley, W. T., Bloch, M. H., Conway, K., \& others. (2018). The conception of the ABCD study: From substance use to a broad NIH collaboration. Developmental Cognitive Neuroscience, 32, 4-7.

White, J. L., Moffitt, T. E., Caspi, A., Bartusch, D. J., Needles, D. J., \& Stouthamer-Loeber, M. (1994). Measuring impulsivity and examining its relationship to delinquency. Journal of Abnormal Psychology, 103(2), 192.

Zucker, R. A., Gonzalez, R., Ewing, S. W. F., Paulus, M. P., Arroyo, J., Fuligni, A., Morris, A. S., Sanchez, M., \& Wills, T. (2018). Assessment of culture and environment in the Adolescent Brain and Cognitive Development Study: Rationale, description of measures, and early data. Developmental Cognitive Neuroscience, 32, 107-120. 


\begin{tabular}{|c|c|c|c|c|c|c|c|c|c|}
\hline & $\begin{array}{c}\text { CD- } \\
n=11,187 \\
\text { n }(\%) / \\
\text { M (SD) }\end{array}$ & $\begin{array}{c}\text { CD+ } \\
n=365 \\
n(\%) / \\
M(S D)\end{array}$ & $X^{2}(d f)$ & $p$ & $\begin{array}{c}\text { Profile 1 } \\
n=131 \\
n(\%) / \\
M(S D)\end{array}$ & $\begin{array}{c}\text { Profile } 2 \\
n=190 \\
n(\%) / \\
M(S D)\end{array}$ & $\begin{array}{c}\text { Profile } 3 \\
n=44 \\
n(\%) / \\
M(S D)\end{array}$ & $X^{2}(d f)$ & $p$ \\
\hline Sex & & & $51.41(1)$ & $<.001$ & & & & $1.52(2)$ & .479 \\
\hline Female & $5409(48 \%)$ & $107(29 \%)$ & & & $34(26 \%)$ & $61(32 \%)$ & $12(27 \%)$ & & \\
\hline Race/Ethnicity & & & $68.06(3)$ & $<.001$ & & & & $13.42(8)$ & .102 \\
\hline White & $5891(53 \%)$ & $150(41 \%)$ & & & $67(51 \%)$ & $66(35 \%)$ & $17(39 \%)$ & & \\
\hline Black & $1622(14 \%)$ & $103(28 \%)$ & & & $26(20 \%)$ & $63(33 \%)$ & $14(32 \%)$ & & \\
\hline Hispanic & $2264(20 \%)$ & $52(14 \%)$ & & & $19(15 \%)$ & $26(14 \%)$ & $7(16 \%)$ & & \\
\hline Other/Multi-racial & $1117(10 \%)$ & $55(15 \%)$ & & & $18(14 \%)$ & $35(18 \%)$ & $6(14 \%)$ & & \\
\hline Family Income & & & $55.54(2)$ & $<.001$ & & & & $5.94(4)$ & .207 \\
\hline$<\$ 50,000$ & $2954(26 \%)$ & $159(44 \%)$ & & & $47(36 \%)$ & $85(45 \%)$ & $23(52 \%)$ & & \\
\hline$\$ 50,000-\$ 100,000$ & $2913(26 \%)$ & $85(23 \%)$ & & & $33(25 \%)$ & $46(24 \%)$ & $6(14 \%)$ & & \\
\hline$\geq \$ 100,000$ & $4378(39 \%)$ & $89(24 \%)$ & & & $37(28 \%)$ & $43(23 \%)$ & $9(20 \%)$ & & \\
\hline Parental Marital Status & & & $73.41(1)$ & $<.001$ & & & & $4.71(2)$ & .097 \\
\hline Married & $7628(68 \%)$ & $171(47 \%)$ & & & $71(54 \%)$ & $79(42 \%)$ & $21(48 \%)$ & & \\
\hline Highest Parent Education & & & $58.03(4)$ & $<.001$ & & & & $4.90(8)$ & .779 \\
\hline Some HS & $529(5 \%)$ & $35(10 \%)$ & & & $12(9 \%)$ & $19(10 \%)$ & $4(9 \%)$ & & \\
\hline HS degree/GED & $1033(9 \%)$ & $53(15 \%)$ & & & $15(11 \%)$ & $33(17 \%)$ & $5(11 \%)$ & & \\
\hline Some College & $2865(26 \%)$ & $124(34 \%)$ & & & $43(33 \%)$ & $64(34 \%)$ & $17(39 \%)$ & & \\
\hline Bachelor's degree & $2863(26 \%)$ & $72(20 \%)$ & & & $27(21 \%)$ & $38(20 \%)$ & $7(16 \%)$ & & \\
\hline Masters or Professional Degree & $3883(35 \%)$ & $81(22 \%)$ & & & $34(26 \%)$ & $36(19 \%)$ & $11(25 \%)$ & & \\
\hline FH Substance Problems & & & $101.80(1)$ & $<.001$ & & & & & \\
\hline $\begin{array}{l}\geq 1 \text { parent with Substance } \\
\text { Problem }\end{array}$ & $2066(18 \%)$ & $141(39 \%)$ & & & $32(24 \%)$ & $48(25 \%)$ & $15(34 \%)$ & $1.48(2)$ & .487 \\
\hline FH Psychopathology & $.38(.47)$ & $.69(.63)$ & $.33(1)$ & .563 & $.62(.53)$ & $.73(.66)$ & $.75(.73)$ & $3.39(1)$ & .184 \\
\hline
\end{tabular}

Note. Chi-square tests performed on data nested by site and family. CD- = youth without a conduct disorder diagnosis; CD+ = youth with a conduct disorder diagnosis; FH = Family History; HS = High School. 
Table 2. Profile Indicator Variables

\begin{tabular}{|c|c|c|c|c|c|c|c|c|c|}
\hline & $\begin{array}{c}\text { CD- } \\
n=11,187 \\
M(S D)\end{array}$ & $\begin{array}{c}\text { CD+ } \\
n=365 \\
M(\mathrm{SD})\end{array}$ & $\begin{array}{l}\text { Wald } \\
X^{2}(1)\end{array}$ & $p$ & $\begin{array}{c}\text { Profile } 1 \\
n=131 \\
\text { M (SD) }\end{array}$ & $\begin{array}{c}\text { Profile } 2 \\
n=190 \\
M(S D)\end{array}$ & $\begin{array}{c}\text { Profile } 3 \\
n=44 \\
M(S D)\end{array}$ & $\begin{array}{c}\text { Wald } \\
X^{2}(2)\end{array}$ & $p$ \\
\hline \multicolumn{10}{|l|}{ UPPS } \\
\hline Positive Urgency & $7.96(2.95)$ & $8.85(3.22)$ & 26.86 & $<.001$ & $7.31(2.67)^{a, b}$ & $9.21(2.97)^{\mathrm{a}, \mathrm{c}}$ & $11.86(3.25)^{b, c}$ & 83.96 & $<.001$ \\
\hline Negative Urgency & $8.46(2.63)$ & $9.58(2.91)$ & 51.33 & $<.001$ & $7.92(2.40)^{a, b}$ & $10.30(2.66)^{\mathrm{a}}$ & $11.36(3.06)^{b}$ & 90.36 & $<.001$ \\
\hline Lack of Planning & $7.72(2.36)$ & $8.37(2.80)$ & 18.82 & $<.001$ & $8.19(2.32)^{a, b}$ & $7.44(2.20)^{a, c}$ & $12.91(12.00)^{b, c}$ & 249.82 & $<.001$ \\
\hline Lack of Perseverance & $7.03(2.25)$ & $7.46(2.42)$ & 11.26 & .001 & $7.77(2.26)^{a, b}$ & $6.58(1.78)^{\mathrm{a}, \mathrm{c}}$ & $10.32(2.86)^{b, c}$ & 84.97 & $<.001$ \\
\hline Sensation Seeking & $9.76(2.67)$ & $10.17(2.83)$ & 7.78 & .005 & $9.24(2.52)^{a, b}$ & $10.51(2.91)^{\mathrm{a}}$ & $11.50(2.56)^{b}$ & 32.13 & $<.001$ \\
\hline \multicolumn{10}{|l|}{ BIS/BAS } \\
\hline BIS & $9.51(3.74)$ & $9.55(4.10)$ & .04 & .839 & $7.56(3.25)^{\mathrm{a}}$ & $10.98(3.88)^{\mathrm{a}}$ & $9.34(4.80)$ & 70.44 & $<.001$ \\
\hline BAS- Reward Response & $11.00(2.91)$ & $11.36(3.18)$ & 4.89 & .027 & $8.70(2.93)^{a, b}$ & $13.00(2.03)^{\mathrm{a}}$ & $12.23(2.73)^{b}$ & 212.20 & $<.001$ \\
\hline BAS- Drive & $4.10(3.04)$ & $5.24(3.41)$ & 38.80 & $<.001$ & $2.65(2.18)^{\mathrm{a}, \mathrm{b}}$ & $6.43(3.01)^{\mathrm{a}}$ & $7.80(3.26)^{b}$ & 227.01 & $<.001$ \\
\hline BAS- Fun Seeking & $5.67(2.63)$ & $6.66(2.97)$ & 39.19 & $<.001$ & $4.04(2.02)^{a, b}$ & $8.01(2.22)^{\mathrm{a}}$ & $8.66(2.71)^{b}$ & 312.45 & $<.001$ \\
\hline CU Traits & $1.09(1.19)$ & $1.99(1.45)$ & 135.45 & $<.001$ & $2.18(1.49)^{a, b}$ & $1.57(1.10)^{\mathrm{a}, \mathrm{c}}$ & $3.25(1.79)^{b, c}$ & 46.02 & $<.001$ \\
\hline
\end{tabular}

Note. Raw mean values reported. Comparisons between CD+ and CD- groups determined from separate general linear models nested by site and family. Comparisons between latent profiles performed using Bolck, Croon, and Hagenaars $(\mathrm{BCH})$ procedure. $\mathrm{M}=$ mean; $\mathrm{SD}=\mathrm{standard}$ deviation; BIS/BAS= behavioral inhibition system/behavioral activation system; CU= callous-unemotional; CD- = youth without a conduct disorder diagnosis; $\mathrm{CD}+=$ youth with a conduct disorder diagnosis. Paired superscripts (e.g., a's) denotes significant group differences at $p<$ .005 . 
Table 3. Psychopathology, Social Functioning, and Neurocognition

\begin{tabular}{|c|c|c|c|c|c|c|c|c|c|}
\hline & $\begin{array}{c}\text { CD- } \\
n=11,187 \\
M(S D)\end{array}$ & $\begin{array}{c}\text { CD+ } \\
n=365 \\
M(S D)\end{array}$ & $\begin{array}{l}\text { Wald } \\
X^{2}(1)\end{array}$ & $p$ & $\begin{array}{c}\text { Profile 1 } \\
n=131 \\
M(S D)\end{array}$ & $\begin{array}{c}\text { Profile 2 } \\
n=190 \\
M(S D)\end{array}$ & $\begin{array}{c}\text { Profile } 3 \\
n=44 \\
M(S D)\end{array}$ & $\begin{array}{l}\text { Wald } \\
X^{2}(2)\end{array}$ & $p$ \\
\hline \multicolumn{10}{|l|}{ CBCL Factor Scores } \\
\hline $\mathrm{P}$ & $-.06(.87)$ & $1.66(1.41)$ & 545.81 & $<.001$ & $1.39(1.40)^{\mathrm{a}}$ & $1.70(1.31)$ & $2.34(1.60)^{\mathrm{a}}$ & 12.47 & .002 \\
\hline INT & $.00(.69)$ & $-.15(1.13)$ & 6.89 & .009 & $-.03(1.07)$ & $-.25(1.17)$ & $-.11(1.05)$ & 3.22 & .200 \\
\hline EXT & $-.05(.72)$ & $1.46(1.56)$ & 325.25 & $<.001$ & $1.11(1.43)^{\mathrm{a}, \mathrm{b}}$ & $1.61(1.59)^{\mathrm{a}}$ & $1.90(1.63)^{b}$ & 12.47 & .002 \\
\hline \multicolumn{10}{|c|}{ School Risk and Protective Factors } \\
\hline School Environment & $19.95(2.80)$ & $19.31(3.40)$ & 225.69 & $<.001$ & $18.76(3.44)^{\mathrm{a}}$ & $19.94(3.29)^{a, b}$ & $18.23(3.28)^{b}$ & 15.98 & $<.001$ \\
\hline School Involvement & $13.06(2.36)$ & $12.81(2.60)$ & 3.04 & .081 & $12.46(2.69)^{\mathrm{a}}$ & $13.31(2.35)^{\mathrm{a}, \mathrm{b}}$ & $11.75(2.89)^{b}$ & 16.83 & $<.001$ \\
\hline School Disengagement & $3.74(1.45)$ & $4.04(1.64)$ & 12.12 & $<.001$ & $4.05(1.64)$ & $3.89(1.65)^{\mathrm{a}}$ & $4.61(1.48)^{\mathrm{a}}$ & 8.17 & .017 \\
\hline \multicolumn{10}{|l|}{ Neighborhood Safety } \\
\hline Youth Report & $4.04(1.08)$ & $3.66(1.31)$ & 29.67 & $<.001$ & $3.78(1.21)$ & $3.59(1.36)$ & $3.57(1.39)$ & 1.85 & .397 \\
\hline Parent Report & $3.90(.97)$ & $3.61(1.11)$ & 23.96 & $<.001$ & $3.78(1.02)$ & $3.50(1.17)$ & $3.60(1.03)$ & 5.59 & .061 \\
\hline \multicolumn{10}{|l|}{ Family Conflict } \\
\hline Youth Report & $2.01(1.94)$ & $2.82(2.23)$ & 45.98 & $<.001$ & $2.42(2.20)^{\mathrm{a}}$ & $2.82(2.09)^{b}$ & $3.98(2.43)^{\mathrm{a}, \mathrm{b}}$ & 14.82 & .001 \\
\hline Parent Report & $2.47(1.92)$ & $4.31(2.29)$ & 225.69 & $<.001$ & $4.09(2.17)$ & $4.57(2.32)$ & $3.82(2.41)$ & 5.49 & .064 \\
\hline Parental Monitoring & $4.39(.51)$ & $4.25(.62)$ & 17.22 & $<.001$ & $4.30(.57)$ & $4.26(.64)$ & $4.07(.66)$ & 4.34 & .114 \\
\hline \multicolumn{10}{|l|}{ Prosocial Behavior } \\
\hline Parent Report & $1.74(.39)$ & $1.33(.55)$ & 218.34 & $<.001$ & $1.32(.53)$ & $1.36(.55)$ & $1.25(.60)$ & 1.44 & .487 \\
\hline GCA & $.08(.85)$ & $-.33(.91)$ & 71.11 & $<.001$ & $-.33(.92)$ & $-.47(.94)$ & $-.41(1.06)$ & 1.74 & .418 \\
\hline
\end{tabular}

Note. Raw mean scores reported. Comparisons between CD+ and CD- groups determined from separate general linear model nested by site and family. Comparisons between latent profiles performed using Bolck, Croon, and Hagenaars $(\mathrm{BCH}) \mathrm{procedure} . \mathrm{M}=\mathrm{mean} ; \mathrm{SD}=$ standard deviation; $\mathrm{CD}-=$ youth without a conduct disorder diagnosis; $\mathrm{CD}+=$ youth with a conduct disorder diagnosis; GCA $=$ general cognitive ability. Paired superscripts (e.g., a’s) denotes significant group differences at $p<.005$. 
Table 4. Latent Profile Model Fit Statistics

\begin{tabular}{|c|c|c|c|c|c|}
\hline & $\begin{array}{l}\text { Profile Proportions } \\
\text { from Posterior } \\
\text { Probabilities }\end{array}$ & AIC & $\begin{array}{l}\text { Sample-Size } \\
\text { Adjusted } \\
\text { BIC }\end{array}$ & $\begin{array}{l}\text { Lo-Mendell- } \\
\text { Rubin } \\
\text { Significance }\end{array}$ & Entropy \\
\hline 1 Profile & Profile 1: $100 \%$ & $11,155.14$ & $11,169.68$ & & 1.00 \\
\hline 2 Profile & $\begin{array}{l}\text { Profile 1: } 42.80 \% \\
\text { Profile 2: } 57.20 \%\end{array}$ & $10,829.93$ & $10,852.47$ & $\begin{array}{l}1 \mathrm{v} 2 \\
p<.001\end{array}$ & 0.73 \\
\hline 3 Profile & $\begin{array}{l}\text { Profile 1: } \mathbf{3 6 . 0 7 \%} \\
\text { Profile 2: } \mathbf{5 1 . 3 3 \%} \\
\text { Profile 3: } \mathbf{1 2 . 5 9 \%}\end{array}$ & $10,696.79$ & $10,727.33$ & $\begin{array}{l}2 \mathrm{v} 3 \\
p=.10\end{array}$ & 0.78 \\
\hline 4 Profile & $\begin{array}{l}\text { Profile 1: } 18.53 \% \\
\text { Profile 2: } 22.21 \% \\
\text { Profile 3: } 46.09 \% \\
\text { Profile 4: } 13.17 \%\end{array}$ & $10,623.08$ & $10,661.62$ & $\begin{array}{l}3 \mathrm{v} 4 \\
p=.12\end{array}$ & 0.76 \\
\hline
\end{tabular}

Note . AIC = Akaike information criterion; $\mathrm{BIC}=$ Bayesian information criterion. Bolded value chosen as best fitting model 
Figure 1. Personality type profiles. BIS = behavioral inhibition system; BAS= behavioral activation system; CU= callousunemotional.

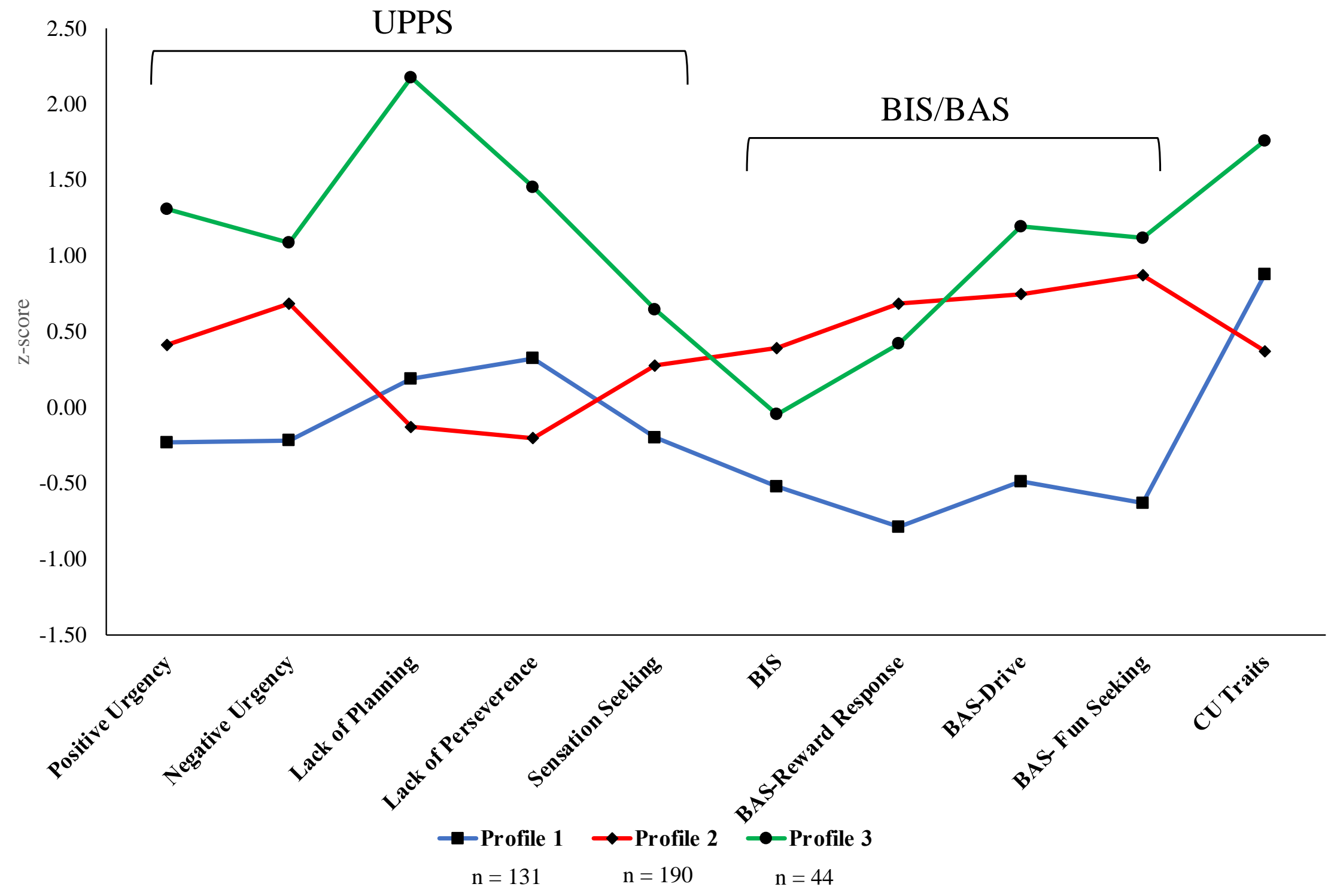


Figure 2. Latent profiles by General Factor of Psychopathology (P), Internalizing (INT), and Externalizing (EXT) factor scores from the Parent Report CBCL. * denotes differences in P, INT, and EXT factor scores that are significantly different at $p<.005$.

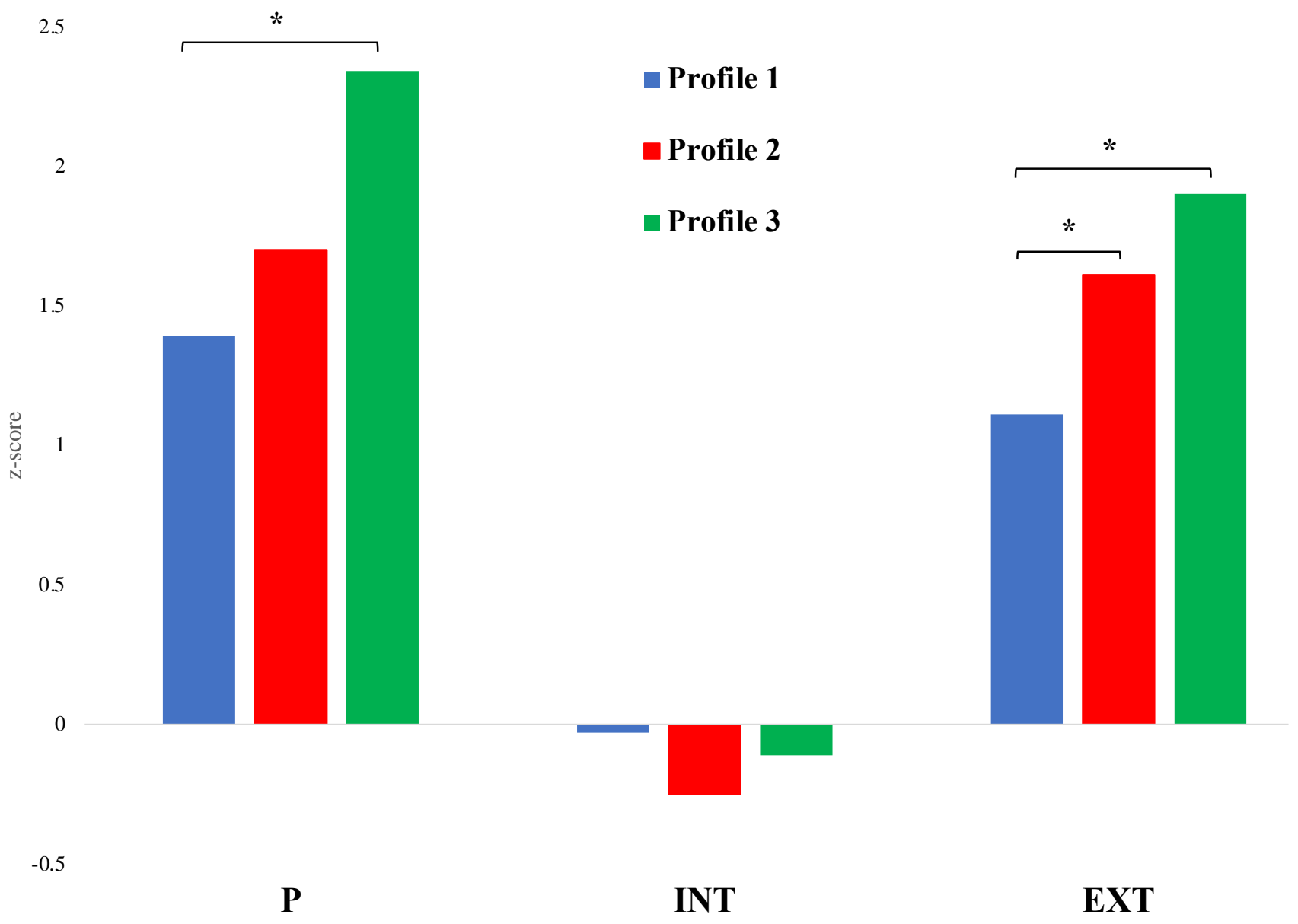


Supplemental Table 1. Parent Report of Psychopathology

\begin{tabular}{|c|c|c|c|c|c|c|c|c|c|}
\hline & $\begin{array}{c}\text { CD }- \\
n=11,187 \\
M(\text { SD })\end{array}$ & $\begin{array}{c}C D+ \\
n=365 \\
M(\mathrm{SD})\end{array}$ & $\begin{array}{l}\text { Wald } \\
X^{2}(1)\end{array}$ & $p$ & $\begin{array}{c}\text { Profile } 1 \\
n=131 \\
M(S D)\end{array}$ & $\begin{array}{c}\text { Profile } 2 \\
n=190 \\
M(S D)\end{array}$ & $\begin{array}{c}\text { Profile } 3 \\
n=44 \\
M(S D)\end{array}$ & $\begin{array}{c}\text { Wald } \\
X^{2}(2)\end{array}$ & $p$ \\
\hline \multicolumn{10}{|l|}{ CBCL } \\
\hline Internalizing & $48.11(10.47)$ & $58.29(10.85)$ & 307.90 & $<.001$ & $56.76(11.94)$ & $58.49(9.92)$ & $61.93(10.59)$ & 7.22 & .027 \\
\hline Anxious/Depressed & $53.31(5.79)$ & $58.38(8.50)$ & 126.18 & $<.001$ & $57.92(8.34)$ & $58.15(8.26)$ & $60.77(9.72)$ & 3.26 & .196 \\
\hline Withdrawn/Depressed & $53.29(5.51)$ & $59.77(9.10)$ & 183.47 & $<.001$ & $60.17(9.82)$ & $59.06(8.24)$ & $61.68(10.24)$ & 3.07 & .215 \\
\hline Somatic Complaints & $54.77(5.97)$ & $58.49(7.36)$ & 90.88 & $<.001$ & $56.93(7.08)^{\mathrm{a}}$ & $58.76(7.21)$ & $61.95(7.64)^{\mathrm{a}}$ & 15.53 & $<.001$ \\
\hline Social Problems & $52.56(4.42)$ & $59.68(7.64)$ & 321.65 & $<.001$ & $58.57(7.40)$ & $59.76(7.18)$ & $62.61(9.44)$ & 6.97 & .031 \\
\hline Thought Problems & $53.54(5.61)$ & $61.39(8.87)$ & 287.72 & $<.001$ & $59.57(9.25)^{\mathrm{a}}$ & $61.79(8.49)$ & $64.52(8.40)^{\mathrm{a}}$ & 10.46 & .005 \\
\hline OC Problems & $53.49(5.90)$ & $59.75(9.11)$ & 170.61 & $<.001$ & $58.98(9.49)$ & $59.79(8.72)$ & $61.91(9.43)$ & 3.13 & .209 \\
\hline Stress Problems & $53.02(5.65)$ & $62.23(8.85)$ & 386.48 & $<.001$ & $61.19(8.98)$ & $62.16(8.33)$ & $65.66(9.99)$ & 6.85 & .032 \\
\hline Externalizing & $45.09(9.76)$ & $64.64(9.25)$ & 1507.47 & $<.001$ & $62.80(9.85)^{\mathrm{a}}$ & $64.93(8.82)^{b}$ & $68.91(7.72)^{\mathrm{a}, \mathrm{b}}$ & 17.37 & $<.001$ \\
\hline Attention & $53.63(5.83)$ & $62.24(9.50)$ & 296.59 & $<.001$ & $60.18(9.56)^{\mathrm{a}}$ & $62.57(8.42)$ & $66.93(11.85)^{\mathrm{a}}$ & 13.30 & .001 \\
\hline Rule Breaking & $52.39(4.28)$ & $64.16(7.81)$ & 773.64 & $<.001$ & $61.85(8.01)^{\mathrm{a}, \mathrm{b}}$ & $64.81(7.58)^{\mathrm{a}, \mathrm{c}}$ & $68.25(5.95)^{b, c}$ & 31.51 & $<.001$ \\
\hline Aggressive & $52.42(4.78)$ & $65.32(10.08)$ & 581.86 & $<.001$ & $63.99(9.30)^{\mathrm{a}}$ & $65.21(10.17)$ & $69.73(10.90)^{\mathrm{a}}$ & 9.70 & .008 \\
\hline \multicolumn{10}{|l|}{ DSM5 Scales } \\
\hline Depressive Problems & $53.40(5.51)$ & $59.87(8.30)$ & 220.72 & $<.001$ & $59.02(8.44)$ & $59.89(8.02)$ & $62.32(8.81)$ & 4.78 & .092 \\
\hline Anxiety Problems & $53.32(5.96)$ & $58.32(8.68)$ & 117.89 & $<.001$ & $57.77(8.79)$ & $58.03(8.10)$ & $61.18(10.28)$ & 4.17 & .124 \\
\hline Somatic Problems & $55.36(6.56)$ & $58.84(7.72)$ & 71.01 & $<.001$ & $57.03(7.44)^{\mathrm{a}}$ & $59.33(7.63)$ & $62.07(7.71)^{\mathrm{a}}$ & 16.05 & $<.001$ \\
\hline ADH Problems & $52.96(5.30)$ & $61.38(8.80)$ & 330.69 & $<.001$ & $59.16(8.65)^{\mathrm{a}}$ & $61.96(8.34)$ & $65.45(9.45)^{\mathrm{a}}$ & 18.13 & $<.001$ \\
\hline OD Problems & $53.16(4.98)$ & $63.15(8.37)$ & 506.34 & $<.001$ & $62.19(8.56)^{\mathrm{a}}$ & $63.00(8.07)$ & $66.64(8.32)^{\mathrm{a}}$ & 9.50 & .009 \\
\hline Conduct Problems & $52.56(4.76)$ & $66.94(8.16)$ & 1053.80 & $<.001$ & $65.01(8.35)^{\mathrm{a}}$ & $67.53(7.95)$ & $70.11(7.18)^{\mathrm{a}}$ & 16.07 & $<.001$ \\
\hline
\end{tabular}

Note. Raw mean t-scored values reported. $\mathrm{M}=$ mean; $\mathrm{SD}=$ standard deviation; $\mathrm{CD}-=$ youth without a conduct disorder diagnosis; $\mathrm{CD}+=$ youth with a conduct disorder diagnosis; $\mathrm{OC}=$ Obsessive-Compulsive; $\mathrm{ADH}=$ Attention Deficit/Hyperactivity; OD = Oppositional Defiant. Significance levels $(p<.005)$ for comparisons between CD+ and CD- groups determined from separate general linear model nested by site and family. Comparisons between latent profiles performed using Bolck, Croon, and Hagenaars (BCH) procedure. Paired superscripts (e.g., a's) denotes significant group differences at $p<.005$. 